\title{
Evaluation of a pharmacist-managed diabetes medication therapy adherence clinic
}

\author{
Received (first version): 6-Aug-2010 Accepted: 2-Oct-2010
}

\begin{abstract}
Patient adherence to prescribed medication regimens is important in diabetes care to prevent or delay microvascular and macrovascular complications such as retinopathy, nephropathy and myocardial infarction. In Penang Hospital, Malaysia, pharmacists collaborate with physicians in diabetes care through a pharmacist-managed Diabetes Medication Therapy Adherence Clinic (DMTAC) in the Endocrine Clinic, in operation since 2006. Objective: To evaluate the effectiveness of the pharmacist-managed DMTAC program in improving glycaemic control, lipid parameters and patients' medication adherence.

Method: A retrospective study among patients enrolled in the DMTAC program was conducted between September 2007 and December 2008. Data was included from patients with a glycosylated haemoglobin $(\mathrm{HbA} 1 \mathrm{c})>8 \%$ and who had completed eight visits with the pharmacists. Medical records and DMTAC forms that provided patients' demographics, medication regimens, adherence and laboratory parameters as well as pharmacists interventions were reviewed. $\mathrm{HbA} 1 \mathrm{c}$, fasting blood glucose (FBG), low-density lipoprotein cholesterol (LDL), triglycerides (TG) and high-density lipoprotein cholesterol (HDL) were evaluated. Documented data of patients' adherence to medication regimen [Modified Morisky Medication Adherence Score (MMMAS); high adherence if score $>8$, medium adherence if score 6 to $<8$ and low adherence if score $<6$ ] was also evaluated. Results: A total of 43 patients (53.5\% females; $46.5 \%$ Malays, $44.2 \%$ Chinese and $9.3 \%$ Indians) were included in the analysis. A mean reduction in $\mathrm{HbA} 1 \mathrm{c}$ of $1.73 \%(\mathrm{p}<0.001)$, mean reduction in FBG of $2.65 \mathrm{mmol} / \mathrm{l}(p=0.01)$ and mean reduction in LDL cholesterol of $0.38 \mathrm{mmol} / \mathrm{l}(\mathrm{p}=0.007)$ were achieved. The difference in TG and HDL cholesterol were not significant. Patients' adherence to medication regimens improved significantly with an increase in the mean MMMAS score from 7.00 to 10.84 $(p<0.001)$ after completion of the DMTAC program. Conclusion: The pharmacist-managed DMTAC program resulted in significant improvements in $\mathrm{HbA} 1 \mathrm{c}$, glucose and LDL cholesterol levels as well as medication adherence in patients with diabetes.
\end{abstract}

Keywords: Diabetes. Medication Adherence. Pharmacists. Malaysia.

\footnotetext{
"Phei Ching LIM. Bachelor of Pharmacy (Hons) Department of Pharmacy, Hospital Pulau Pinang. Penang (Malaysia).

Kelvin LIM. Bachelor of Pharmacy (Hons). Pill House Sdn. Tanjung Bungah (Malaysia).
}

\author{
EVALUACIÓN DE UNA CLÍNICA \\ FARMACÉUTICA PARA EL \\ CUMPLIMIENTO DEL TRATAMIENTO EN \\ DIABETES
}

\section{RESUMEN}

El cumplimiento de la medicación en los pacientes diabéticos es importante para prevenir o retrasar complicaciones micro y macrovasculares tales como retinopatía, neuropatía e infarto de miocardio. En el Hospital de Penang, Malasia, los farmacéuticos colaboran con los médicos en diabetes a través de una clínica farmacéutica para el cumplimiento del tratamiento en diabetes

(DMTAC) en la clínica endocrinológica, operando desde 2006.

Objetivo: Evaluar la efectividad del programa de la DMTAC en la mejora del control glucémico, de parámetros lipídicos y de cumplimiento de la medicación por los pacientes.

Métodos: Entre septiembre 2007 y diciembre 2008 se realizó un estudio retrospectivo entre los pacientes atendidos en el programa de la DMTAC. Se incluyeron datos de pacientes con hemoglobina glicosilada (HbA1c) >8\% y que habían completado 8 visitas con el farmacéutico. Se revisaron los historiales médicos y los formularios de la DMTAC que proporcionaron datos demográficos de los pacientes, medicación, cumplimiento y parámetros de laboratorio, así como las intervenciones de los farmacéuticos. La HbA1c, glucemia en ayuno, colesterol de lipoproteínas de baja densidad (LDL), triglicéridos (TG) y colesterol de lipoproteínas de alta densidad (HDL). También se evaluaron los datos de cumplimiento de los pacientes [Modified Morisky Medication Adherence Score (MMMAS); alto cumplimiento si la puntuación $>8$,

cumplimiento medio si puntuación de 6 a 8 y bajo cumplimiento si puntuación <6].

Resultados: Se incluyó en el análisis un total de 43 pacientes (53,5\% mujeres; $46.5 \%$ Malayos, $44.2 \%$ Chinos and $9.3 \%$ Indios). Se obtuvo una reducción media de HbA1c de 1,73\% ( $<<0,001)$, de glucemia de $2,65 \mathrm{mmol} / \mathrm{l}(\mathrm{p}=0,01)$ y de colesterol LDL de $0.38 \mathrm{mmol} / \mathrm{l}(\mathrm{p}=0,007)$. La diferencia en TG y colesterol HDL no fue significativa. Después de completar el programa de la DMTAC, el cumplimiento de los pacientes de su medicación mejoró significativamente con un aumento en la puntuación del MMMAS de 7,00 a 10,84 $(\mathrm{p}<0,001)$.

Conclusión: el programa farmacéutico de la DMTAC produjo mejorías significativas en los niveles de $\mathrm{HbA} 1 \mathrm{c}$, glucosa y colesterol LDL, así 
como en el cumplimiento de la medicación de los pacientes con diabetes.

Palabras clave: Diabetes. Cumplimiento de la medicación. Farmacéuticos. Malaysia.

\section{INTRODUCTION}

The World Health Organization (WHO) reported that 171 million people were living with diabetes mellitus in the year 2000, and that amount is estimated to double by the year 2030. ${ }^{1}$ In Malaysia, the prevalence of type 2 diabetes for those aged above 30 years was $14.9 \%$ in the year 2006 . $^{2}$ Poorly controlled diabetes is associated with development of macro- and micro-vascular complications. Therefore, intensive glycaemic control is important in decreasing microvascular and macrovascular complications in type 1 and type 2 diabetes. ${ }^{3-5}$

In order to have good glycaemic control, patient adherence to medication regimens is vital. However, adherence is still a challenge and many patients are noncompliant with their oral hypoglycaemic agents and insulin. ${ }^{6}$ Evidence has proven that patient education improves patients' adherence and subsequently improves glycaemic control. $^{7}$ Pharmacists play a significant role in educating patients through routing counseling, which helps to improve patient adherence. ${ }^{8}$

Several studies have shown that collaboration of pharmacists with physicians in diabetes care improved glycaemic control., ${ }^{9,10}$ In Malaysia, pharmacists collaborate with physicians in diabetes care through Diabetes Medication Therapy Adherence Clinic (DMTAC). Penang Hospital is the first centre to start the DMTAC program, which has been operating since 2006 in a specialized diabetes endocrine clinic.

Patients with poor glycaemic control (glycosylated haemoglobin, $\mathrm{HbA} 1 \mathrm{c}>8 \%$ ) are enrolled in the DMTAC program. They are identified through physician referrals or selected by the pharmacists during their routine follow-up. Once enrolled, patients are scheduled to meet the pharmacists every one to two months interval for eight consecutive visits. During each visit, individualized counseling and education are provided. The education includes an explanation of diabetes and its complications, symptoms of hypo- and hyperglycaemia and its treatment, medications, diet and exercise, and other topics that are related to diabetes. During every visit, patient compliance to medication regimens is assessed using the Modified Morisky Medication Adherence Score (MMMAS) ${ }^{11}$; [high adherence if score $>8$, medium adherence if score 6 to $<8$ and low adherence if score <6]. In addition, the pharmacists perform blood glucose monitoring and insulin dosing adjustments according to patients' self-monitoring blood glucose levels. During a joint physician-pharmacist followup, pharmacists will suggest titration of medication doses and propose additional medication which is deemed necessary (for instance antidiabetic agents, lipid lowering drugs or aspirin).

However, the DMTAC program is still new and evolving. Thus, there is not much data about the effectiveness of this program. The purpose of the study is to evaluate the effectiveness of the DMTAC program in improving glycaemic control, lipid parameters and patients' adherence in a multiethnic population in a specialized endocrine clinic.

\section{METHODS}

A retrospective cross-sectional study of the Diabetes Medication Therapy Adherence Clinic (DMTAC) Program was conducted in Penang Hospital, Malaysia, to evaluate the effectiveness of the program by assessing the glycaemic control, lipid parameters and medication adherence of patients enrolled between September 2007 and December 2008. This study was approved by the Medical Research Ethics Committee, Ministry of Health, Malaysia.

The inclusion criteria were diabetes mellitus patients in the Endocrine Clinic, Penang Hospital, Malaysia, between 15 and 75 years of age who had a glycosylated haemoglobin (HbA1c) more than $8 \%$ and were indentified through physician referrals or selected by the pharmacists. Only data of patients who had completed eight visits with the pharmacists were reviewed. Patients that were lost to follow-up or still had on-going follow-up with the pharmacists were excluded.

Medical records and DMTAC forms were retrieved and reviewed. The records provided information about patient demographics, medication regimens and laboratory parameters. Records regarding patient adherence with the Modified Morisky Medication Adherence Score (MMMAS) were included. In addition, documented pharmacists' interventions that included suggestions on dosage adjustments as well as additions of antidiabetic agents, statins and insulin were reviewed.

The primary outcome was mean difference in $\mathrm{HbA} 1 \mathrm{c}$ by comparing pre- and post-intervention values. The secondary outcome measures included difference in fasting blood glucose (FBG), lowdensity lipoprotein cholesterol (LDL), high-density lipoprotein cholesterol (HDL), triglycerides (TG) as well as patients' adherence to medication regimens. Patient medication regimens and use of metformin, sulfonylureas, thiazolidinedione, alpha-glucosidase inhibitors, insulin and statins were reviewed.

Data were analyzed using SPSS Version 16.0 for Windows. Collected data of HbA1c, FBG and LDL were normally distributed and therefore the paired ttest was conducted to compare means. Data distribution of HDL, TG and MMMAS were skewed and therefore the Wilcoxon signed-rank test was used. Results were statistically significant if the $p$ value was $<0.05$.

\section{RESULTS}

Seventy-six patients were enrolled in the DMTAC program between September 2007 and December 
2008. Forty-three patients $(57 \%)$ completed the eight visits with the pharmacists and had pre- and post-intervention data whereas 33 patients $(43 \%)$ were either still scheduling visits with the pharmacists or were lost to follow-up. Therefore, data of the 43 patients that completed the eight visits were included in this study. Demographics and medication regimens of the 43 patients selected were shown in Table 1. Use of oral hypoglycaemic agents was shown in Figure 1.

\begin{tabular}{|c|c|}
\hline \multicolumn{2}{|c|}{$\begin{array}{lrrrr}\text { Table 1. } & \text { Patient Demographics and Medication } \\
\text { Regimens } & & & \\
\end{array}$} \\
\hline Demographics & $\begin{array}{l}\text { No. of Patients }(\%) \text {, } \\
n=43\end{array}$ \\
\hline Age $(y)$ & $47.93(\mathrm{SD}=2.18)$ \\
\hline \multicolumn{2}{|l|}{ Gender } \\
\hline Males & $20(46.5 \%)$ \\
\hline Females & $23(53.5 \%)$ \\
\hline \multicolumn{2}{|l|}{ Race or Ethnicity } \\
\hline Malay & $20(46.5 \%)$ \\
\hline Chinese & $19(44.2 \%)$ \\
\hline Indian & $4(9.3 \%)$ \\
\hline \multicolumn{2}{|l|}{ Type of Diabetes } \\
\hline Type 1 & $7(16.3 \%)$ \\
\hline Type 2 & $36(83.7 \%)$ \\
\hline $\mathrm{BMI}^{*}$ & $26.71(\mathrm{SD}=0.84)$ \\
\hline$<18.5$ & $2(4.6 \%)$ \\
\hline $18.5-24.9$ & $14(32.6 \%)$ \\
\hline $25-29.9$ & $15(34.9 \%)$ \\
\hline$\geq 30$ & $12(27.9 \%)$ \\
\hline \multicolumn{2}{|l|}{ Treatment } \\
\hline \multirow{4}{*}{$\begin{array}{r}\mathrm{OHAs}^{\dagger}+\text { basal insulin } \\
{\text { Full insulin }+\mathrm{OHA}^{\dagger}}^{\dagger} \text { Insulin only } \\
\end{array}$} & $6(14.0 \%)$ \\
\hline & $13(30.2 \%)$ \\
\hline & $16(37.2 \%)$ \\
\hline & $8(18.6 \%)$ \\
\hline$x^{2}+x^{2}$ & $41(95.3 \%)$ \\
\hline
\end{tabular}

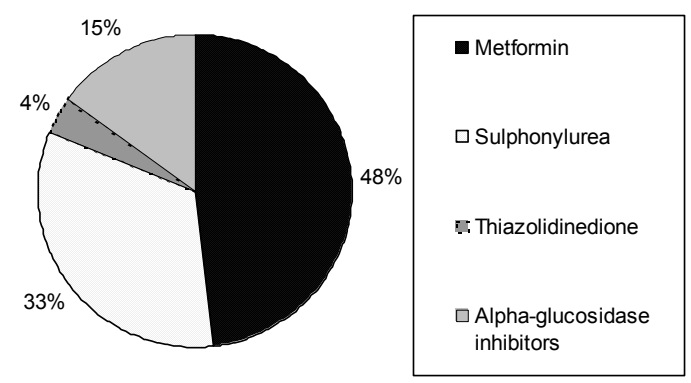

Figure 1: Use of oral hypoglycaemic agents.

Of the 43 patients that completed eight visits, 15 (34.9\%) patients were overweight with a body mass index (BMI) $\geq 25$ but less than 30 , and $12(27.9 \%)$ patients were obese with a $B M I \geq 30$. The pharmacists made a total of 52 interventions (Figure 2). The acceptance rate of physicians on DMTAC pharmacists' interventions was satisfactory.
The mean pre- and post-intervention outcome measures are shown in Table 2. There was a significant difference of $-1.73 \%$ for mean $\mathrm{HbA} 1 \mathrm{c}$, which decreased from $10.82(S D=0.31)$ to 9.09 $(S D=0.24) \quad(p<0.001)$. Twenty-six patients $(61 \%)$ had achieved at least 1\% drop in $\mathrm{HbA} 1 \mathrm{c}$ after completion of the DMTAC program (Figure 3). The reduction of $2.65 \mathrm{mmol} / \mathrm{l}(\mathrm{p}=0.011)$ in mean $\mathrm{FBG}$ was also significant. Mean LDL cholesterol also reduced significantly by $0.38 \mathrm{mmol} / \mathrm{l} \quad(p=0.007)$. However, reduction of mean TG was not significant. There was a reduction of mean HDL cholesterol but the reduction of $0.05 \mathrm{mmol} / \mathrm{l}(p=0.333)$ was not significant. Patient adherence improved significantly with mean MMMAS increasing from medium adherence, $7.00(\mathrm{SD}=0.61)$ to high adherence, $10.84(S D=0.10)(p<0.001)$. After the intervention, $100 \%$ of the patients were high adherence.
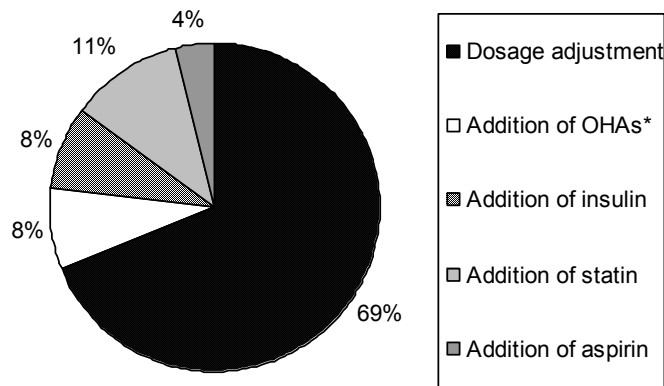

Figure 2: Intervention completed by DMTAC pharmacists. ${ }^{*} \mathrm{OHA}=$ oral hypoglycaemic agent

Percentage of Patients with a Specified Reduction in Glyc osylated Hae moglobin

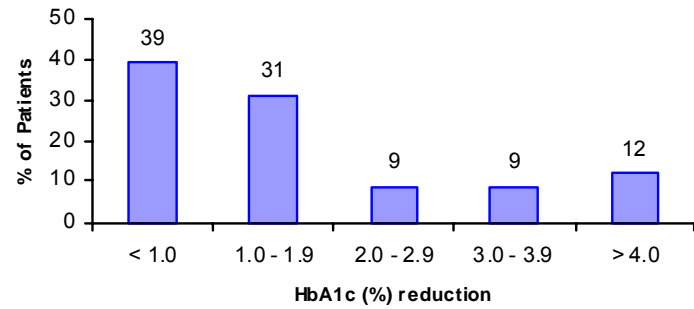

Figure 3: Percentage of Patients with a specified reduction in HBA1C

\section{DISCUSSION}

This study showed that the pharmacist-managed DMTAC program significantly improved glycaemic control, LDL cholesterol and patient adherence. The mean $\mathrm{HbA} 1 \mathrm{c}$ reduction of $1.73 \%$ was similar to a retrospective chart review $(n=109)$ completed by

\begin{tabular}{|l|c|c|c|c|}
\hline Table 2. Changes in glycaemic control, lipid parameters and patient medication adherence \\
\hline Outcome measures & $\begin{array}{c}\text { Pre- } \\
\text { Intervention }\end{array}$ & $\begin{array}{c}\text { Post- } \\
\text { Intervention }\end{array}$ & $\begin{array}{c}\text { Mean } \\
\text { difference }\end{array}$ & P-value \\
\hline HbA1c $(\%)$ & $10.82(0.31)$ & $9.09(0.24)$ & -1.73 & $<0.001$ \\
\hline FBG $(\mathrm{mmol} / \mathrm{l})$ & $11.34(0.85)$ & $8.69(0.62)$ & -2.65 & 0.011 \\
\hline LDL-C $(\mathrm{mmol} / \mathrm{l})$ & $3.22(0.18)$ & $2.84(0.18)$ & -0.38 & 0.007 \\
\hline TG $(\mathrm{mmol} / \mathrm{l})$ & $2.00(0.20)$ & $1.88(0.15)$ & -0.12 & 0.631 \\
\hline $\mathrm{HDL}-\mathrm{C}(\mathrm{mmol} / \mathrm{l})$ & $1.19(0.06)$ & $1.14(0.04)$ & -0.05 & 0.333 \\
\hline Patient Adherence (MMMAS) & $7.00(0.61)$ & $10.84(0.10)$ & 3.84 & $<0.001$ \\
\hline${ }^{*}$ Data are mean (SD) & \multicolumn{5}{|l}{} \\
\hline
\end{tabular}


Kiel et al. ${ }^{12}$, which reported a significant improvement in glycaemic control of patients enrolled in a pharmacist-coordinated diabetes management program. In prospective studies conducted by Leal et al. ${ }^{13}$ and Coast-Senior et al. ${ }^{14}$, the mean $\mathrm{HbA} 1 \mathrm{c}$ reduction of $2 \%$ after intervention was greater compared to this study as pharmacists had the rights to prescribe medications. UKPDS has proven that every $1 \%$ reduction of $\mathrm{HbA} 1 \mathrm{c}$ is associated with a $37 \%$ risk reduction of microvascular complications. ${ }^{4}$ This study showed that $61 \%$ of patients in the DMTAC program had at least a one percent drop of HbA1c. Therefore, the DMTAC program in Penang Hospital had an indirect impact on microvascular endpoints in these $61 \%$ of patients, which as a result improved these patients' quality of life.

The mean reduction of FBG $(2.65 \mathrm{mmol} / \mathrm{l})$ was greater compared to retrospective study by Anaya et $a{ }^{15}{ }^{15}$ which reported a mean FBG reduction of $1.47 \mathrm{mmol} / \mathrm{l}$. In the Veterans Administration Pharmacist Program $(n=23)$ where every patient was on insulin therapy, the FBG reduction was greater, at $3.61 \mathrm{mmol} / \mathrm{I}^{14}$

Additionally, patients' LDL cholesterol decreased significantly from $3.22 \mathrm{mmol} / \mathrm{l}$ to $2.84 \mathrm{mmol} / \mathrm{l}$. The reduction was greater compared to a study performed by Leal et al. ${ }^{13}$ that reported a mean reduction of $0.28 \mathrm{mmol} / \mathrm{l}$. However, other retrospective studies have shown that patients' LDL cholesterol did not decrease significantly at the end of the studies. ${ }^{12,15}$ Ninety-five percent of patients in the DMTAC program were taking statins and fulfilled the requirement of statin treatment for all patients with diabetes over 40 years of age as stated in the Ministry of Health Clinical Practice Guidelines. ${ }^{16}$ The two patients that were not on statins had type 1 diabetes and were less than 40 years of age. Although several landmark trials ${ }^{20-22}$ have shown that the use of statins can reduce triglycerides by 10 to $20 \%$, the reduction of triglycerides was only $6 \%$ and not significant in this study. The difference in HDL cholesterol was also not significant, similar to study performed by Leal et al. ${ }^{13}$ However, mean $\mathrm{HDL}$ cholesterol was greater than $1 \mathrm{mmol} / \mathrm{l}$ and achieved the target. ${ }^{16}$

Pharmacists provided education and counselling to patients enrolled in the DMTAC program. Prior to enrollment the patients had poor glycaemic control and their mean adherence was 'medium' with mean Modified Morisky Medication Adherence Score (MMMAS) of 7.00. It is important for patients to understand the nature of his or her disease and medication regimens to improve their adherence and clinical outcomes. ${ }^{17}$ Patient adherence improved significantly in this study and these results are consistent with a study showing that pharmacists providing patient education improved patient adherence. ${ }^{8}$ However, this is in contrast to study performed by Odegard et al. which reported no improvement in adherence in a pharmacistmanaged group. ${ }^{18}$

Finally, there are limitations in this study. It is a retrospective review of a small population of patients that may not represent the entire diabetes population. The duration of the study was short and long term efficacy of this program is unknown. In addition, there was no control group in this study; therefore, it may be difficult to compare the effectiveness of the DMTAC program with physician-managed care. However, the intention of this study was to show the effectiveness of the Diabetes Medication Therapy Adherence Clinic program which may increase the awareness of other healthcare professionals to pharmacists' contribution in diabetes care. It may also serve as a baseline for the development of this program in other health care institutions in Malaysia, and provides preliminary data regarding the effectiveness of the DMTAC program in Malaysia. Therefore, a randomized controlled prospective study is necessary to address these limitations.

\section{CONCLUSIONS}

The pharmacist-managed Diabetes Medication Therapy Adherence Clinic program significantly improved patients' glycaemic control and lowdensity lipoprotein cholesterol. Improvement of these clinical markers will eventually delay or decrease the incidence of unwanted complications of diabetes mellitus. In addition, patient adherence to medication regimens improved significantly. The findings of this study provide evidence of the effectiveness of pharmacists' involvement in diabetes care.

\section{ACKNOWLEDGEMENTS}

We thank the physicians in Endocrine Unit, Penang Hospital for supporting the DMTAC program. Our gratitude also extends to Ms. Oiyammaal Chelliah and Ms. Tajunisah Mohd Eusoff for their assistance in the preparation of this article.

\section{CONFLICT OF INTEREST}

The authors have no financial or other conflict of interests that could inappropriately influence or bias the authors' decision in relation to the manuscript submitted. No sponsorship or funding.

\section{References}

1. Wild S, Roglic G, Green A, Sicree R, King H. Global Prevalence of Diabetes. Estimates for the year 2000 and projections for 2003. Diabetes Care. 2004;27:1047-1053.

2. Mafauzy M. Diabetes Mellitus in Malaysia. Med J Malaysia. 2006;61(4):397-398.

3. The DCCT Research Group. The effect of intensive treatment of diabetes on the development and progression of longterm complications in insulin-dependent diabetes mellitus. N Engl J Med. 1993;329(14):977-986. 
4. U.K. Prospective Diabetes Study Group. Association of glycaemia with macrovascular and microvascular complications of type 2 diabetes (UKPDS 35): prospective observational study. BMJ. 2000;321(7258):405-412.

5. U.K. Prospective Diabetes Study Group. Intensive blood-glucose control with sulphonylureas or insulin compared with conventional treatment and risk of complications in patients with type 2 diabetes (UKPDS 33). Lancet. 1998;352(9131):837-853.

6. Cramer JA. A systemic review of adherence with medications for diabetes. Diabetes Care. 2004;27(5):1218-1224.

7. Goudswaard AN, Stolk RP, Zuithoff NP, de Valk HW, Rutten GE. Long-term effects of self-management education for patients with Type 2 diabetes taking maximal oral hypoglycaemic therapy: a randomized trial in primary care. Diabet Med. 2004;21(5):491-496.

8. Lindenmeyer A., Hearnshaw H., Vermeire E., Van Royen P., Wens J., Biot Y. Interventions to improve adherence to medication in people with type 2 diabetes mellitus: a review of the literature on the role of pharmacists. $\mathrm{J}$ Clin Pharm Ther. 2006;31(5):409-419.

9. Renders CM, Valk GD, Griffin SJ, Wagner EH, Eijk Van JT, Assendelft WJ. Interventions to improve the management of diabetes in primary care, outpatient, and community settings: a systematic review. Diabetes Care. 2001;24:1821-1833.

10. Ramser KL, Sprabery LR, George CM, Hamann GL, Vallejo VA, Dorko G.S, Kuhl DA. Physician-pharmacist collaboration in the management of patients with diabetes resistant to usual care. Diabetes Spectrum. 2008;21(3):209214.

11. Morisky DE., Ang A., Krousel-Wood M., Ward HJ. Predictive Validity of a Medication Adherence Measure for Hypertension Control. J Clin Hypertens (Greenwich). 2008;10(5):348-354.

12. Kiel PJ, McCord AD. Pharmacist impact on clinical outcomes in a diabetes disease management program via collaborative practice. Ann Pharmacother. 2005:39(11):1828-1832.

13. Leal S., Glover JJ, Herrier RN., Felix A. Improving quality care in diabetes through a comprehensive pharmacist-based disease management program. Diabetes Care. 2004;27:2983-2984.

14. Coast-Senior EA, Kroner BA, Kelley CL, Trilli ET. Management of patients with type 2 diabetes by pharmacists in primary care clinics. Ann Pharmacother. 1998;32:636-640.

15. Anaya JP, Rivera JO, Lawson K, Garcia J, Luna J Jr, Ortiz M. Evaluation of pharmacist-managed diabetes mellitus under a collaborative drug therapy agreement. Am J Health Syst Pharm. 2008;65:1841-1845.

16. Clinical Practice Guidelines: Management of Type 2 Diabetes Mellitus (4th Edition). Ministry of Health Malaysia 2009 May.

17. Shillinger D, Grumbach K, Piette J, Wang F, Osmond D, Daher C, Palacios J, Sullivan GD, Bindman AD. Association of health literacy with diabetes outcomes. JAMA. 2002;288(4):475-482.

18. Odegard PS, Goo A, Hummel J, Williams KL, Gray SL. Caring for poorly controlled diabetes mellitus: A randomized pharmacist intervention. Ann Pharmacother. 2005;39(3):433-440.

19. WHO. Obesity: Preventing and managing the global epidemic. Report on a WHO Consultation on Obesity, Geneva, 3-5 June 1997. Geneva: World Health Organization; 1998.

20. Scandinavian Simvastatin Survival Study Group. Randomised trial of cholesterol lowering in 4444 patients with coronary heart disease: the Scandinavian Simvastatin Survival Study (4S). Lancet. 1994;344:1383-1389.

21. Downs JR, Clearfield M, Weis S, Whitney E, Shapiro DR, Beere PA, Langendorfer A, Stein EA, Kruyer W, Gotto AM Jr. Primary prevention of acute coronary events with lovastatin in men and women with average cholesterol levels: results of AFCAPS/TexCAPS. Air Force/Texas Coronary Atherosclerosis Prevention Study. JAMA. 1998;279:1615-1622.

22. Sever PS, Dahlof B, Poulter NR, Wedel H, Beevers G, Caulfield M, Collins R, Kjeldsen SE, Kristinsson A, Mclnnes GT, Mehlsen J, Nieminen M, O'Brien E, Ostergren J. Prevention of coronary and stroke events with atorvastatin in hypertensive patients who have average or lower-than-average cholesterol concentrations, in the Anglo-Scandinavian Cardiac Outcomes Trial-Lipid Lowering Arm (ASCOT-LLA): a multicentre randomised controlled trial. Lancet. 2003;361:1149-1158. 